\title{
Understanding the health-disease process and the birth of Social Medicine
}

\section{Compreensão do processo saúde-doença e o nascimento da Medicina Social}

Isadora Sabrina Ferreira dos Santos ${ }^{1}$, Laís Eduarda Silva de Arruda ${ }^{1}$, Luís Roberto da Silva ${ }^{1}$, Erlene Roberta Ribeiro dos Santos ${ }^{2}$

${ }^{1}$ Acadêmicos do Curso de Bacharelado em Saúde Coletiva do Centro Acadêmico de Vitória, Universidade Federal de Pernambuco - CAV/UFPE, Pernambuco, Brazil.

${ }^{2}$ Departamento de Saúde Coletiva, Centro Acadêmico de Vitória, Universidade Federal de Pernambuco, Pernambuco, Brazil.

\begin{abstract}
Social Medicine was born from the discussion in the $19^{\text {th }}$ century about the health-disease process, being one of the precursors of health promotion, in which it was seen as a technology of the time for the healthdisease process of the population. The health-disease process transforms over time, in which it is essential to have a universal thought that understands that the gradients of mortality and morbidity involve socioeconomic classes. The purpose of this review is to revisit the theories that have grounded the definitions of the health-disease process throughout the history of mankind and the contribution of social medicine to the current context of collective health. It is relevant to address that the living and working conditions of the population were directly linked to their health situation, social, cultural, and psychological factors that influence the occurrence of diseases and illnesses. Therefore, promotion, prevention, cure, and rehabilitation were initial measures based on health education and actions used by the State. Moreover, the field of social medicine strongly contributed to improve and implement the model of primary health care (PHC), focused on the community, considering the social determinants of the health situation of the communities, in addition to the individual aspects of each being.

Keywords: Health-disease process; Social medicine; Collective health.
\end{abstract}

\section{Introduction}

Social medicine emerged from the $19^{\text {th }}$ century discussion on the health-disease process, being one of the precursors of health promotion, in which it was seen as a technology of the time for the health-disease process of the population. ${ }^{1}$ Thus, the health-disease process that is closely linked to the economic context of society has been transformed over time, due to the fact that scientific explanations required better cohesion and coherence with what the social body needed. ${ }^{2}$
As a result, the health-disease process undergoes transformations over time, in which universal thinking is essential, understanding that the gradients of mortality and morbidity involve socioeconomic classes, so that people with lower incomes are vulnerable to a worse health situation. Thus, the transformations that the health-disease process undergoes over the years is fundamental to intimately understand the whole context that involves the illness and the health of the social body, from the health situation to the socioeconomic context. ${ }^{3}$ 
Furthermore, social medicine, which is born with a very intríscacious critique of the biomedical model, is beginning to punctuate itself as a model based on social determinants, which goes against the history and transformation of the health-disease process over the years, which begins to break with the idea of illness as a sin of the epochs. ${ }^{2}$

Thus, the objective of this review is to revisit the theories that have underpinned the definitions of the health-disease process throughout human history and the contribution of social medicine to the current context of collective health.

\section{Health-disease process}

The conceptions of health and illness began to develop from the Sumerian people as well as in ancient Egypt, where illness was seen and analyzed as a divine punishment, having a magical-religious conception resulting from the action of forces alien to the organism that they introduced by sin or curse. In addition, the health-disease process manifested itself in the field of arts (through works, culture (through tables, teas, preparations, rituals of magic), and science already in the most current centuries (Figure 1). ${ }^{4}$

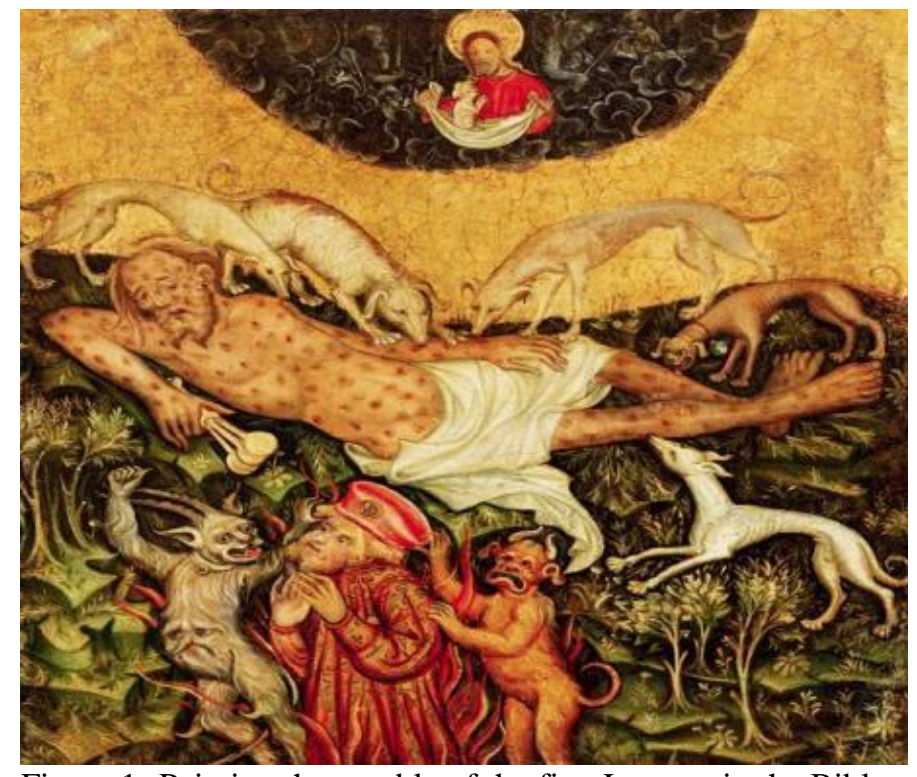

Figure 1- Painting the parable of the first Lazarus in the Bible, from stock photos.

Source: Adventures in History - UOL Digital Repository

Moreover, the Hebrew people did not necessarily believe that sickness was a divine sin, but a sign of it, as a way of alerting the human being to his or her sins. However, it is possible to see that sickness was a sign of disobedience to the divine commandments, and that this sickness proclaimed in a visible way, such as leprosy (Figure $2)^{4}$

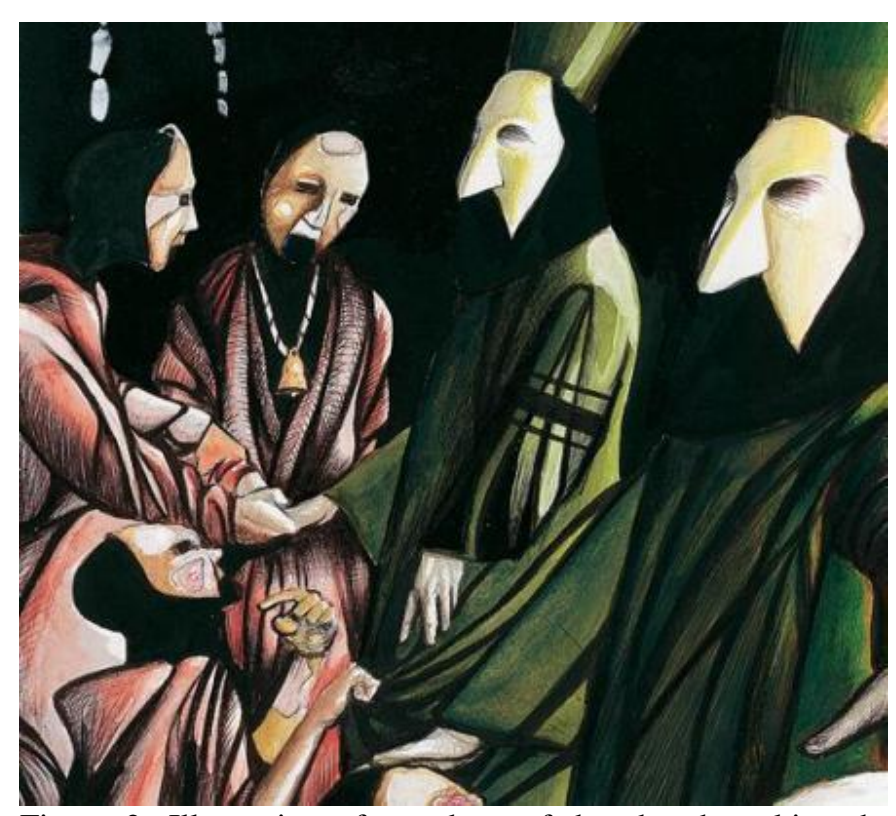

Figure 2- Illustration of members of the church making the diagnosis of leprosy, by Alexandre Teles.

Source: Adventures in History - UOL Digital Repository. 
In the Middle Ages, illness is still seen as a relationship to sin, and healing as a matter of faith, care for the sick in most cases was given to the religious orders that administered the hospital, but not as a place of healing, but of rest for the sick. ${ }^{4}$

Among the theories that explain the healthdisease process, in Brazil, at the end of the 19th century, the primitivist conception attributed to the disease a situation of single cause and/or supernatural cause, often associated with a punishment from heaven for the sick. As a concrete cause of disease generation, it was also accepted the belief in the theory of miasmas, in which disease is associated to contact, sense of touch, atmospheric conditions (Figure 3).

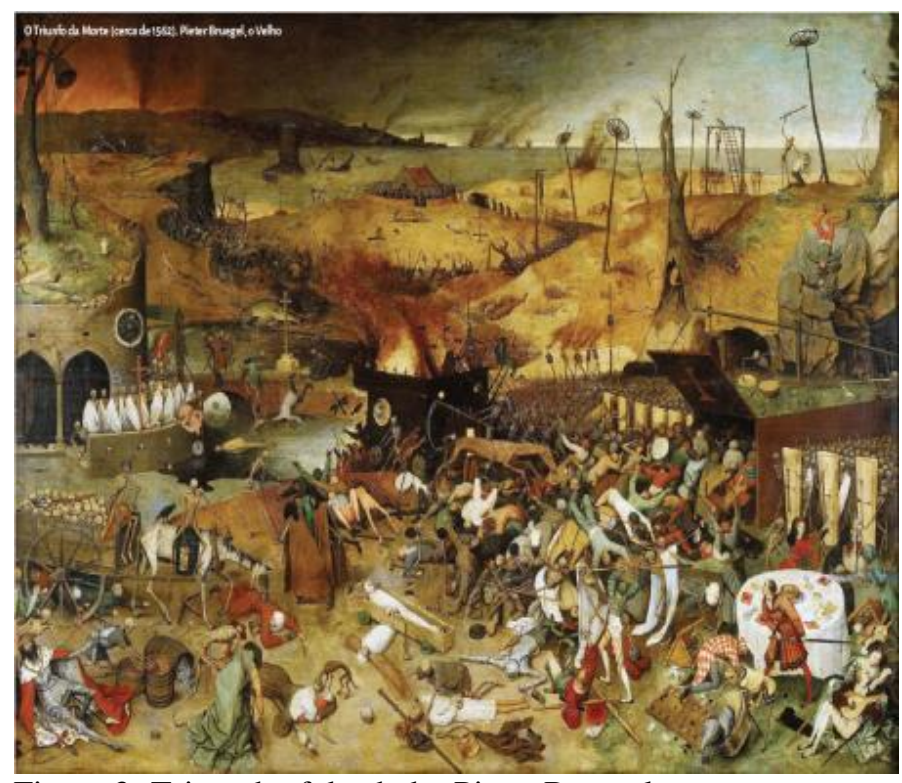

Figure 3- Triumph of death, by Pieter Bruegel.

Source: Repositório digital história das artes.

From the empirical experiences (initial evidence), improvement of the scientific method and the observation of other aspects that influenced the health-disease condition, the model based on the natural history of the disease (ecological triad) was expanded, bringing concepts related to the pre- pathogenesis and pathogenesis period, "explaining", at the time, the processes of illness coming from specific etiological agents, for each disease". 5

When this theory was exhausted, based on the transformations in the demographic and epidemiological characteristics of the Brazilian population, marked in the 1950's, when noncommunicable diseases occupy a prominent place in the morbidity and mortality scenario in the country, the model did not present robustness to explain the causes, thus allowing the breaking of this paradigm and discussion of the theory based on the social determination of the Health-Disease process, strengthened in the 1960's, in Latin America.

Presenting greater explanatory power to the social phenomena of health and illness, in the context of subordination to the capitalism of the countries of the world and increasing social inequality (social medicine of the models of France, and Germany), this theory bases the origin of illness, in the current of thought of social pathology, bringing the need for the treatment of social and political processes for intervention in the healthdisease process.

\section{Social Medicine and contribution to the health- disease process}

Social Medicine comes with three subdivisions. State medicine, which developed in Germany, with the aim of intervening in the stagnation of economic development, seeking better alternatives to improve the actions of the State, since the economy was unstructured and several 
employees were paralyzed. Soon, their superiors were forced to make a process of planning and organization. ${ }^{6}$

The second modality, developed in France, with urban medicine the State now has a regulated unification of urban power for economic and political reasons. And, from the third modality of construction that social medicine begins to develop in England, characterized as the medicine of the poor. With industrial development, as well as the growth of the proletariat, the law of the poor was born. $^{6}$

Thus, Social Medicine sought alterrnatives that integrated social sciences, epidemiology, social determination of diseases and health policies. With the objective of contributing, through interactive individual and collective models in the healthdisease dimension. ${ }^{7}$

Thus, it is relevant to address that the living and working conditions of the population were directly linked to their health situation, social, cultural and psychological factors that influence the occurrence of diseases and illnesses. Therefore, promotion, prevention, cure and rehabilitation were initial measures based on health education and actions used by the State aiming at improving the quality of life (Figure 4). ${ }^{8}$

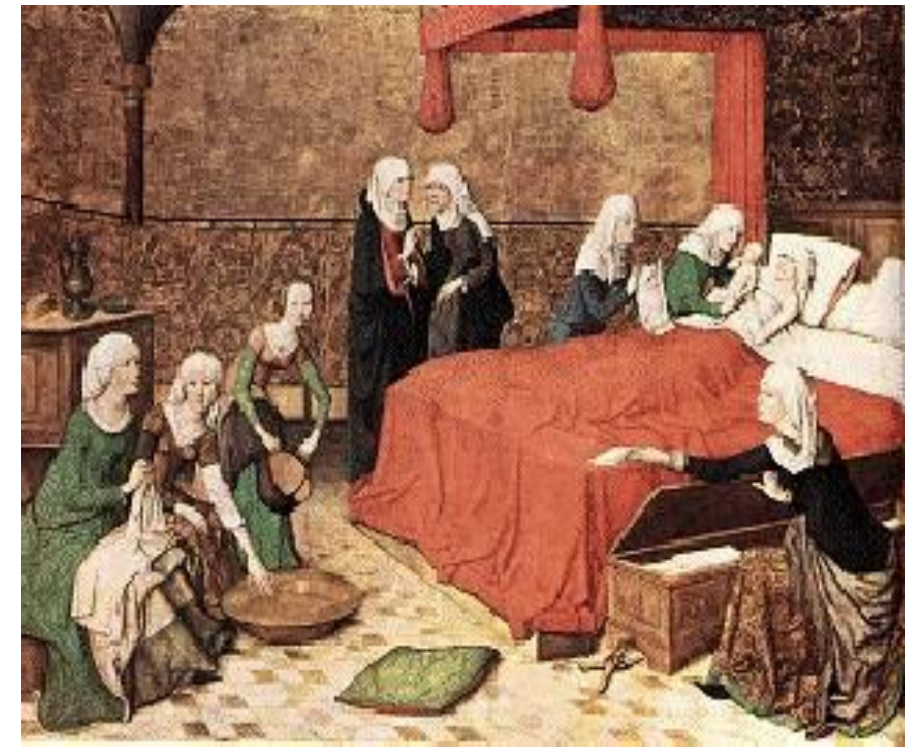

Figure 4- Diseases in the Middle Ages Source: Interactive History

In this way, the way they benefited from medical assistance, the population would also have to submit to medical controls, and from this the popular resistance to this control would begin to emerge. From this perspective, the need to integrate the essential pillars arises, that is, clinical practice carries out the study of the disease in the individual, verifying case by case, and epidemiology studies the factors that determine the behavior of the frequency and distribution of diseases in population groups. ${ }^{4}$

The objective of Epidemiology being to produce knowledge and technologies, which help in the promotion and contribution of the health disease process, capable of promoting individual health through measures of collective reach. In order to evaluate the creation of equitable, universal and integrative public policies (Figure 5). ${ }^{9}$ 


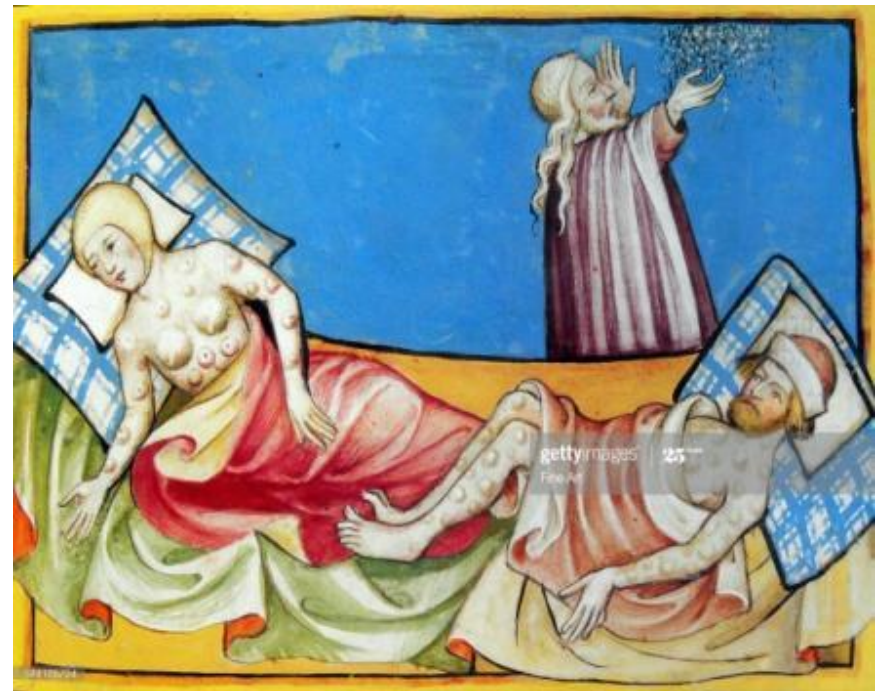

Figure 5- Illustration of individuals affected by bubonic plague.

Fonte: Getty imagens

\section{Preventive Medicine, collective health care}

Preventive medicine has strongly contributed to the establishment of the field of collective health in the world and in Brazil. In the 18th century, with the hygienic policies that occurred in Western Europe, the need for hygiene to maintain individual and collective health was discussed. It brought the State's responsibility in formulating policies and norms of interest to health, and even at the advent of the Industrial Revolution, the impact of labor conditions on the population's health situation was already perceived (Figure 6). ${ }^{10}$

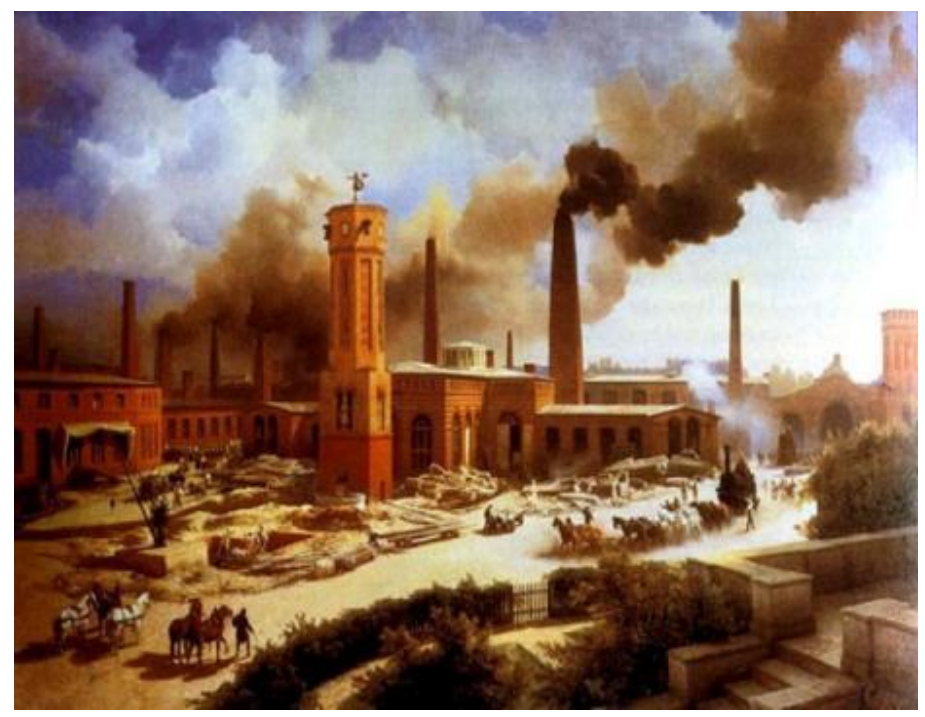

Figure 6 - Illustration of the II Industrial Revolution.

Source: Repositório digital professorando história, 2017.

Michel Foucault already discussed that social medicine was the result of the development of knowledge, techniques and ways that work with the social aspect of the world, such as the development of biopolitics (management strategies that involve the social and biological aspects of the population). ${ }^{7,8}$ Virchow, in his time, already pointed out how socioeconomic issues implied in the health conditions of the population. ${ }^{10}$

In Brazil, during the VIII National Health Conference, the principles of social medicine were commented and worked on, contributing to the Brazilian sanitary reform, increase of productions related to social aspects of health and formation of the collective health field in the country. It also brought criticism to the extremely assistentialist and biologic models of health care of the time, which are still present today, however, it brought the possibility of thinking about health in a broad and complex way. ${ }^{11}$

The field of social medicine has strongly contributed to the improvement and implementation of the primary health care (PHC) model, focused on the community, considering the social determination of the health situation of the communities, besides the individual aspects of each being. Social engagement is essential to the functioning of PHC, since the connection with the territory allows health professionals to know the problems of that place, identify possible causes and solutions to meet the health needs of the population, 
considering its totality and not only the individual clinical picture. ${ }^{12}$

The family health strategy (ESF), a model of PHC adopted in Brazil, has in its essence the basis of social medicine, since it aims to meet the health needs of the population in a resolute manner and considering the integrality of the users. ${ }^{11}$ The promotion of health is one of the main bases of the ESF and consists of a group of strategies that aim at meeting individual and collective health needs and expanding the quality of life. ${ }^{13}$

Epidemiology plays an essential role in the development of collective health care, since it is from it and its tools that it is possible to elaborate and analyze the health situation of individuals living in a given territory and, thus, have support to the planning of actions, elaboration of priorities and strategies for intervention in health needs in that locality.

It is clear that the field of collective health has had a strong influence on the foundations of social medicine, through the first strategies to understand the social determination of the health situation and illness of the population. And, over the years, this field has grown and fostered the critique of the reductionist vision of understanding the population's illness and establishing health as a right of all in the 1988 Federal Constitution. ${ }^{11}$

\section{Conclusion}

The health illness process is directly linked to the birth of social medicine, as well as its contribution to health advances. Since it was from the understanding of the need to be cared for, that a new vision about measures to be used was thought.

Thus, despite being the individual who gets sick, health must be thought in the collective dimension, since it is essential to recognize the social impact, the environment and the social determinants that the individual is inserted, in order to understand the factors that contribute to the illness, so that health needs are met.

Given this, it is understood that social medicine has a great impact in transforming the way the health-disease process is understood, since it is possible to perceive that this whole process begins to develop better from its birth, when the access to health begins to become more effective and concrete.

With this, it is noticeable the need to strengthen health care processes that are based on the principles and conceptions of social medicine. It is essential to produce studies focused on the history of human health care models with the purpose of understanding how the current models were built and knowing their bases.

\section{References}

1. Sigerist HE (1996) Health. In HE Sigerist. Medicine and human welfare. Yale University Press. Reproduced in Journal of Public Health, 17(2).

2. Ianni AMZ (2019) Saúde Pública e Colonização da Natureza. Physis, 19(4):1029-1050.

3. Especialização em Saúde da Família. 1st ed. Online: UNASUS. Processo saúde- doença. 2012:4-6. Available from: https://www.unasus.unifesp.br/biblioteca_virtual/esf/2/u nidades_conteudos/unidade01/unidade01.pdf

4. Calaça CE. Capítulos da história social da medicina no Brasil. Hist. cienc. saude-Manguinhos. 


\section{5;12( 2 ) : 557-566. Available from: https://doi.org/10.1590/S0104- 59702005000200022 .}

5. Puttini RF, Pereira JA, Oliveira LR (2010) Modelos explicativos em saúde coletiva: abordagem biopsicossocial e auto-organização. Physis, 20(3):753767.

6. Foucault M (1984) O nascimento da Medicina Social. In: Machado R, organizador. Microfísica do poder, 79-98.

7. Cordeiro H (2004) O Instituto de Medicina Social e a luta pela reforma sanitária: contribuição à história do SUS. Physis, 14(2):343-362.

8. Buss PM, Pellegrini FA (2007) A Saúde e seus Determinantes Sociais. PHYSIS: Rev. Saúde Coletiva, 17(1):77-93.

9. Rouquayrol M, Gurgel ZM. Epidemiologia \& saúde. (7) Rio de Janeiro: Medbook, 2013.

10. Scliar Moacyr (2007) História do conceito de saúde. Physis, 17(1):29-41.
11. Borde E, Hernández-Álvarez M, Porto MFS (2015) Uma análise crítica da abordagem dos Determinantes Sociais da Saúde a partir da medicina social e saúde coletiva latino-americana. Saúde debate, 39(106):841-854.

12. Osmo A, Schraiber LB (2015) O campo da Saúde Coletiva no Brasil: definições e debates em sua constituição. Saude soc, 24( Suppl 1):205-218.

13. Malta DC, Santos MAS, Stopa SR, Vieira JEB, Melo EA, Reis AAC (2016) A Cobertura da Estratégia de Saúde da Família (ESF) no Brasil, segundo a Pesquisa Nacional de Saúde, 2013. Ciênc. saúde coletiva, 21( 2 ): 327-338.

Autor para correspondência Isadora Sabrina Ferreira dos Santos isadorasabrina18@gmail.com Recebido: 26 de julho de 2020 Aceito: 11 de dezembro de 2020 